\title{
A Study on Non Neoplastic Lesions of Skin and its Morphological Spectrum; In a Tertiary Care Hospital
}

\author{
Dr. Majety Dora Venkata Ramnath, Dr. Siva Ranjan D*
}

Assistant Professor, Nimra Institute of Medical Sciences, Andhra Pradesh, India

\author{
DOI: $10.36348 /$ sjpm.2020.v05i05.011 \\ | Received: 11.05.2020 | Accepted: 18.05.2020 | Published: 21.05.2020 \\ *Corresponding author: Dr. Siva Ranjan D
}

Abstract

Background: In India more than 50\% of general hospital skin out-patient attendance consists of infections which are acute and usually recurrent like Scabies, Pyodermas, Superficial fungal infections, Parasitic and viral infections, Eczemas, Acne, Vitiligo, Pigmentary changes, Psoriasis, Lichen planus, Leprosy etc. The present study was therefore designed with the aim of studying the histopathological features of various skin diseases. So that, the clinicians can manages the case efficiently. Aims \& Objectives: To find the clinicopathological correlation and to study the histopathological features of Non-neoplastic skin lesions. Materials \& Methods: A total of 93 skin biopsies either Punch or Incision biopsies which were received in the department of histopathology were stained with Hematoxylin\& Eosin, and studied microscopically. Results: Out of 93 cases, only $20(21.5 \%)$ cases are not similar in clinical diagnosis and histopathological diagnosis but remaining 73 (78.5\%) cases has similar diagnosis both clinicopathologically. Conclusion: histopathological study and comparing the clinical diagnosis serves as a very valuable diagnostic tool to understand and explain the pathology of various skin lesions.

Keywords: Skin biopsies, Non-neoplastic skin lesions, clinicopathological study.

Copyright @ 2020: This is an open-access article distributed under the terms of the Creative Commons Attribution license which permits unrestricted use, distribution, and reproduction in any medium for non-commercial use (NonCommercial, or CC-BY-NC) provided the original author and sources are credited.

\section{INTRODUCTION}

The pattern of skin diseases in most parts of India is a consequence of poverty, malnutrition, overcrowding, poor hygiene, illiteracy and social backwardness. In India more than $50 \%$ of general hospital skin out-patient attendance consists of infections which are acute and usually recurrent like Scabies, Pyodermas, Superficial fungal infections, Parasitic and viral infections, Eczemas, Acne, Vitiligo, Pigmentary changes, Psoriasis, Lichen planus, Leprosy etc.

In addition, problems such as population explosion, urban migration, overcrowding, illiteracy, poverty, starvation and deforestation have resulted in conditions deleterious to human health in our country. In fact the ecological factors are the root of geographic distribution of diseases. It is the interaction of the skin with external influences, such as climate, physical, chemical, biological agents, socio-cultural and economic factors in relation to skin diseases.

India, being a vast country with diverse population groups has different customs, presents a variety of dermatoses. Females in India traditionally apply cosmetics like - Henna, Kajal, and Bindi. Contact dermatitis has been ascribed to all these agents. Walking bare foot or in slippers, which is common in India, can lead to many dermatoses by predisposing to trauma. Eg: Mycetoma, Sporotrichosis, Cutaneous TB, and Dracunculosis.

Pathological studies have documented the extent of spread of various skin lesions and have made significant contribution to the understanding of etiology and pathogenesis. Pathologic studies have played an important role in the diagnosis of various skin lesions [1]. The present study was therefore designed with the aim of studying the histopathological features of various skin diseases. So that the clinicians can manage the case efficiently[1].

In this study the aim is to study the histopathological features of Non-neoplastic skin lesions. And the objective of the study is Clinically diagnosed as Non-Neoplastic disorders/diseases, such as Bullous pemphigoid, Palmoplantar keratoderma (PPKD), Amyloidosis, Lichen planus, Psoriasis etc. were taken for histopathological correlation and the patients were studied for the age and sex distribution, 
clinical manifestations and histopathological correlation of the diseases.

\section{MATERIALS AND METHODS}

The present study was done for a period of 18 months in a tertiary care teaching hospital in Telangana. Skin biopsies were received in the Department of histopathology from the Outpatient and Inpatient department of Dermatology. Clinical details were recorded. During this period a total of 93 cases of Nonneoplastic skin diseases were studied. The patients were selected, irrespective of age, sex, socioeconomic status and residence. Cases were taken up for study after appropriate consent.

Fully developed lesions were taken for biopsy, because of their being more informative. Adequate biopsy included epidermis, dermis and subcutaneous fat. Specimens which were received in histopathology department were fixed in 10\% Formalin, after fixation for 8-24 hours biopsy specimens were processed in an automatic tissue processor.
The processing included a succession of increasing concentration of isopropyl alcohol for dehydration then through Xylene for clearing and finally through two changes of hot melted paraffin for impregnation. The specimens were edge embedded with epidermis upwards in the still liquid paraffin which was allowed to harden. The block was then cut on a rotary microtome in to sections of about 3 to 5 microns thickness. All the skin biopsies were stained with Hematoxylin\& Eosin, and examined. Special stains like $\mathrm{AFB}, \mathrm{PAS}$ etc. were done in required cases.

\section{RESULTS}

In the present study the age of the patients ranged from 1 to 80 years (mean age being 40.7). Maximum number of cases was seen in the age group of 41-50 years, 22 cases (23.6\%). Minimum number of cases was seen in the age group of 71-80 years, 1 case $(0.93 \%)$. The oldest was 80 years old, a case the Psoriasis and the youngest was 5 years old, a case of Scrofuloderma. Age wise distributions of cases were shown in figure 1 .

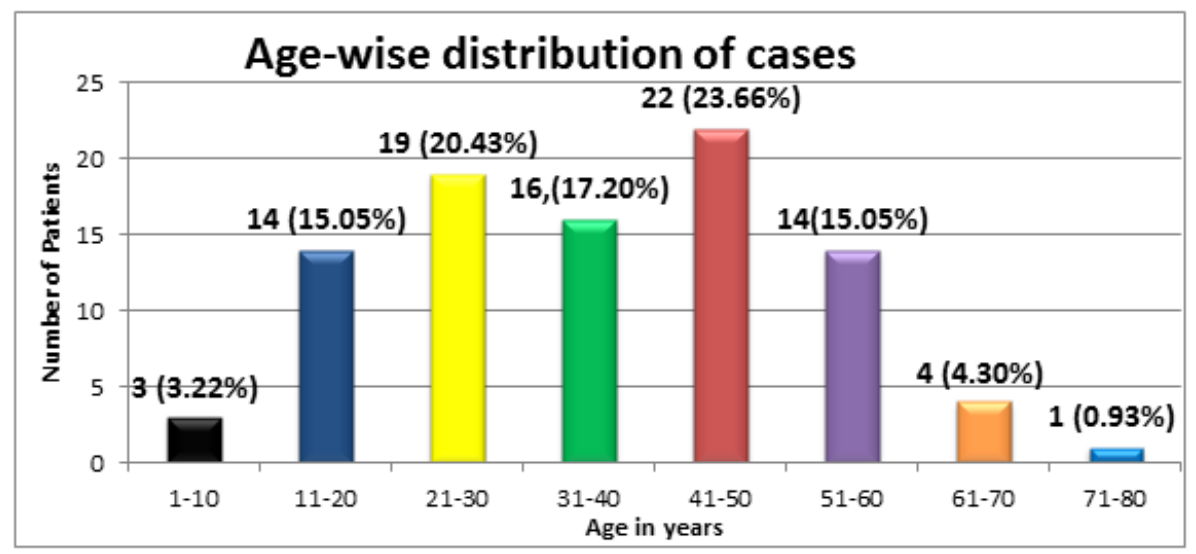

Fig-1: Age-wise distribution of cases

Out of the total 93 patients in this study, $48(51.61 \%)$ were male and $45(48.39 \%)$ were female patients. Male to female ratio was 1.08:1 which showed male preponderance. In males more number of cases were Psoriasis (13) followed by Palmoplantar keratoderma (11). In females more number of cases were Palmoplantar keratoderma (9) followed by Scrofuloderma (5). The type of skin lesion and distribution among male and female were given in Table 1.

Table-1: Showing the type of skin lesions $(n=93)$

\begin{tabular}{|c|c|c|c|}
\hline TYPE OF SKIN LESIONS & $\begin{array}{c}\text { NUMBER OF } \\
\text { CASES (n=93) }\end{array}$ & $\begin{array}{c}\text { MALE } \\
\mathbf{n}(\%)\end{array}$ & $\begin{array}{c}\text { FEMALE } \\
\mathbf{n}(\%)\end{array}$ \\
\hline Vesiculobullous disorders & 3 & $2(66.67)$ & $1(33.33)$ \\
Bullous pemphigoid & 4 & 0 & $4(100.00)$ \\
\hline Pemphigus vulgaris & 16 & $13(81.25)$ & $3(18.75)$ \\
\hline Papulosquamous disorders & 10 & $5(50.00)$ & $5(50.00)$ \\
\hline Psoriasis & 5 & $2(40.00)$ & $3(60.00)$ \\
\hline Lichen planus & 1 & & $1(100.00)$ \\
Metabolic disorders & 2 & 0 & $1(50.00)$ \\
Cutaneous amyloidosis & 4 & $1(50.00)$ & $2(50.00)$ \\
\hline Vasculitis & & $2(50.00)$ & \\
Urticarial vasculitis & & &
\end{tabular}




\begin{tabular}{|c|c|c|c|}
\hline Disorders of Keratinization & 20 & $11(55.00)$ & $9(45.00)$ \\
\hline Palmoplantar keratoderma & & & \\
Collagen vascular disorders & 3 & 0 & $3(100)$ \\
Systemic sclerosis & 1 & 0 & $1(100)$ \\
Systemic lupus erythematosus & 4 & $3(75.00)$ & $1(25.00)$ \\
Discoid lupus erythematosus & 1 & 0 & $1(100)$ \\
\hline Dermatitis & 3 & $2(66.67)$ & $1(33.33)$ \\
Eczema & 2 & $1(50.00)$ & $1(50.00)$ \\
Erythroderma & 2 & & \\
Prurigo nodularis & 1 & 0 & 0 \\
Cutaneous tuberculosis & 6 & $1(16.67)$ & $5(100)$ \\
Tuberculosis verrucosa cutis & 5 & $3(60.00)$ & $2(40.33)$ \\
Papulonecrotic tuberculids & & & \\
Scrofuloderma & &
\end{tabular}

The correlation between the clinical diagnoses with its histopathological diagnosis were shown in Table 2. The lesions like bullous pemphigoid, amyloidosis, urticarial vasculitis, eczema, scleroderma, SLE, DLE, and PPKD, which were diagnosed clinically showed same features in microscopic study and diagnosed as same diagnosis histopathologically. Out of 93 cases, only $20(21.5 \%)$ cases are not similar in clinical diagnosis and histopathological diagnosis but remaining $73(78.5 \%)$ cases has similar diagnosis both clinicopathologically.

Table-2: showing the Correlation between clinical and histopathological diagnosis

\begin{tabular}{|c|c|c|c|}
\hline Clinical diagnosis & No. of cases [n(\%)] & Histological diagnosis & $\begin{array}{c}\text { No. of cases correlated } \\
{[\mathbf{n}(\boldsymbol{\%})]}\end{array}$ \\
\hline Bullous pemphigoid & $3(03.22)$ & Bullous pemphigoid & $03(100.00)$ \\
\hline Pemphigu vulgaris & $4(04.30)$ & Pemphigus vulgaris & $03(75.00)$ \\
\hline Psoriasis & $16(17.20)$ & Psoriasis & $7(62.50)$ \\
\hline Lichen planus & $10(10.75)$ & Lichen planus & $3(75.00)$ \\
\hline Pleva & $4(04.30)$ & Pleva & $5(100.00)$ \\
\hline Amyloidosis & $5(05.37)$ & Amyloidosis & $1(100.00)$ \\
\hline Urticarial vasulitis & $1(01.07)$ & Urticarial Vasulitis & $20(100.00)$ \\
\hline HSP & $2(02.15)$ & HSP & $1(100.00)$ \\
\hline PPKD & $20(21.50)$ & PPKD & $2(66.67)$ \\
\hline Eczema & $1(01.07)$ & Eczema & $1(50.00)$ \\
\hline Erythroderma & $3(03.22)$ & Erythroderma & $4(100.00)$ \\
\hline Purigonodularis & $2(02.15)$ & Prurigo nodularis & $3(100.00)$ \\
\hline SLE & $1(01.07)$ & SLE & $3(50.00)$ \\
\hline DLE & $4(04.30)$ & DLE & $2(40.00)$ \\
\hline Systemic sclerosis & $3(03.22)$ & Systemic sclerosis & $2(100.00)$ \\
\hline Scrofuloderma & $6(06.45)$ & Scrofuloderma & $1(100.00)$ \\
\hline Lupus vulgaris & $5(05.37)$ & Lupus vulgaris & \\
\hline Tuberculosis verrucosa & $2(02.15)$ & Tuberculosis verrucosa cutis & \\
\hline cutis & $1(01.07)$ & Papulonecrotic tuberculids & \\
\hline Papulonecrotic tuberculids & & & \\
\hline
\end{tabular}

\section{DISCUSSION}

Morphology alone is seldom specific and cannot be used as diagnostic tool for identification of specific diseases. Adequate clinical data and workup in combination with pathological resources can help in elucidation of specific etiology and good clinicopathologic correlation.In the present study on Nonneoplastic skin lesions, the patients were studied for the age and sex distribution, clinical manifestations and the clinico-histopathological correlation of the diseases. A total of 93 clinically diagnosed cases of Non-neoplastic skin lesions attending the outpatient department of dermatology, STD and leprosy, in a tertiary care hospital for a period of 18 months, were studied for the clinico-histopathological correlation.

In the present study of clinically diagnosed 93 cases of skin disorders, 20 cases was PPKD which was the commonest, followed by 16 cases of Psoriasis and 10 cases of Lichen planus followed by six cases of Scrofuloderma, Lupus vulgaris and Amyloidosis five cases each, DLE , Pemphigus vulgaris and PLEVA four 
cases each respectively. Similarly the study by Felix Boon Bin Yap[2], of Malayasia and by Th. Bijayanti and $\mathrm{G}$ Zamzachin[3] of Imphal showed that commonest cases were eczema followed by Papulosquamous disorders and vesiculobullous disorders.

In our present study $73(78.49 \%)$ cases were clinico-histopathologically correlated out of 93 cases. A similar study by Felix Boon Bin Yap ${ }^{47}$ et al, 368 $(92.00 \%)$ out of 400 cases from their study showed similar diagnosis both clinically and histopathologically.

Psoriasis is a chronic relapsing disease of the skin characterized by variable clinical features. The lesions are classified as erythrosquamous, which indicates that both the vasculature (erythema) as well as the epidermis (increased scale formation) is involved[4]. Prevalence rate of psoriasis is 0.1 to $3 \%$ worldwide [5]. In the present study 16 cases are clinically diagnosed as Psoriasis with a male predominance and predominantly seen in 40 to 60 years of age. Clinical and pathological correlation was seen in 10 cases $(62.50 \%$ correlation). Non correlated cases were histologically diagnosed as PPKD, Lichen planus, Pemphigus vulgaris and 3 cases were having Nonspecific findings. Similarly Shilpa Mehta et al. [6] in their study revealed that $68.8 \%$ cases were having similar diagnosis both histopathologically and clinically.

Lichen Planus is a common inflammatory, papulosquamous disorder of unknown aetiology, characterized by small flat topped, shiny, polygonal, violaceous papules that may coalesce into plaque [7]. Seen in all parts of the world[8]. In this study Lichenplanus comprised of 10 cases with equal male and female distribution and predominantly seen in 3050years. Clinical and pathological correlation was seen in 7 cases $(70 \%)$. One case was diagnosed as Lichen simplex chronics and two cases were having nonspecific findings.A Clinico histopathological study of 75 cases of lichen planus [9] showed the commonest affected age group was 31-40 years with male and female distribution of cases were equal as our present study.

Palmoplantar keratodermas (PPKD) are a diverse group of multietiological disorders of keratinization, characterized by an excessive thickening of the stratum corneum of palms and soles. It may be the only change or a part of a more widespread manifestation of these diseases $[10,11]$. In our study 20 cases of PPKD was seen in 20-40 years of age group. Clinical and pathological correlation was seen in all the 20 cases (100.00\% correlation). In our PPKD cases, male preponderance was seen (males $55 \%$, females 45 $\%)$ which is in concordance with previous studies. In a study by Mahajan PM et al. [12] $64.63 \%$ of cases were males. Similarly, Chopra et al. [13] reported male preponderance in their study of acquired PPKD, where $55 \%$ of the cases were males. This male preponderance of palmoplantar keratoderma is probably due to various outdoor occupations and activities resulting in predisposition to trauma caused by manual labor and working or walking barefoot.

\section{CONCLUSION}

To conclude $78.5 \%$ cases are clinicopathologically correlated. $100.0 \%$ correlation is seen in bullous pemphigoid, amyloidosis, urticarial vasculitis, eczema, scleroderma, SLE, DLE, and PPKD. The present study has emphasized the role of histopathologic examination in cutaneous disorders and diseases. It serves as a very valuable diagnostic tool to understand and explain the pathology of various skin lesions. With appropriate clinical diagnosis or differential diagnosis provided by dermatologists or clinicians, the concordance levels can definitely be improved.

\section{REFERENCES}

1. Chandrasekhar, H.R. (1994). Basic Dermatopathology. In: Valia RG, Valia AR editors. IADVL text book of and Atlas of Dermatology. Bombay: Bhalani Publishing House; 34-51.

2. Yap, B., \& Boon, F. (2009). Dermatopathology of 400 skin biopsies from Sarawak. Indian journal of dermatology, venereology and leprology, 75(5), 518-519.

3. Devi, T. B., \& Zamzachin, G. (2006). Pattern of skin diseases in Imphal. Indian journal of Dermatology, 51(2), 149.

4. Valia, R.G., Valia, A.R.(2001). Eczemas. Valia RG Valia AR. In: IADVL textbook and atlas of dermatology. $2^{\text {nd }}$ ed. Mumbai: Bhulani press; 412452.

5. Maize, J.C. (1998). Dermatitis with epidermal hyperplasia. In: Maize JC, Burgdorf WH, Hunt ME, editors. Cutaneous pathology, 1st ed. Philadelphia: Churchill Livingstone; 169-95.

6. Mehta, S., Singal, A., Singh, N., \& Bhattacharya, S. N. (2009). A study of clinicohistopathological correlation in patients of psoriasis and psoriasiform dermatitis. Indian Journal of Dermatology, Venereology, and Leprology, 75(1), 100.

7. Lewis, G.M., Wheeler, Jr. C.E.(1967). The maculo papulosquamous diseases. In: Practical dermatology. 3rd ed. Philadelphia: W.B. Saunders Company; 207-30.

8. Gibson, L.E., Perry, H.O.(1992). Papulosquamous eruptions and exfoliative dermatitis. In: Moschella SL, Hurley HJ, editors. Dermatology. 3rd ed. Philadelphia: WB Saunders Company; 607-51.

9. Lichen, P. (2000). A Clinico-histopathological. Indian J Dermatol Venerol Leprol, 66(4): 193-95.

10. Judge, M.R., McLean, W.H.I., Munro, C.S.(2004). Disorders of keratinization. In: Burns T, Breathnac S, Cox N, Griffiths C. Rook's Textbook of 
Dermatology. $7^{\text {th }}$ ed. Blackwell Publishing Company; 341-50.

11. Arnold Jr H.L., Odom, R.B., James, W.D.(1990). Andrews's diseases of the skin: clinical dermatology. $8^{\text {th }}$ ed. Philadelphia (PA): WB Saunders.

12. Mahajan, P. M., Gharpuray, M. B., \& Kulkarni, V. (1994). Clinical and histopathological study of palmoplantar keratoderma. Indian Journal of Dermatology, Venereology, and Leprology, 60(5), 258.

13. Chopra, A., \& Gill, S. S. (1997). Hyperkeratosis of palms and soles: Clinical study. Indian Journal of Dermatology, Venereology, and Leprology, 63(2), 85. 